Gut, 1983, 24, 1064-1066

Endoscopy

\title{
Endoscopy and infection
}

Report and recommendations of the Endoscopy Committee of the British Society of Gastroenterology, accepted by the Annual Business Meeting of members, Exeter, September 1981.

There are numerous published and unpublished reports of serious infection related to gastrointestinal endoscopy. The Endoscopy Committee is increasingly concerned about the lack of awareness of this problem. In 1980, a survey of 52 large endoscopy units showed that less than half were using effective disinfecting schedules. These recommendations are based on a detailed review of the literature, workshops involving endoscopists, microbiologists, instrument and disinfection experts, and on comments received following discussion of a draft document circulated in April 1981.

\section{A Microbiological hazards during endoscopy}

1 Patient to patients transfer. Organisms can be carried from patient to patient on contaminated endoscopes. There have been several Salmonella epidemics. Opportunistic organisms such as Pseudomonas frequently colonise endoscopic equipment which has not been adequately disinfected, and such organisms have been instilled into a succession of patients during endoscopy lists. This passage has resulted in serious primary infections in patients whose immunity is compromised, and during routine ERCP when contaminated contrast is injected into stagnant duct systems. A similar mechanism could lead to intestinal colonisation, with resulting spread of antibiotic resistant organisms throughout a hospital. There is a risk of transmitting virus infections such as hepatitis.

2 Bacteraemia. Gastrointestinal endoscopy (like many other investigative procedures) can result in transient bacteraemia; there is a theoretical risk of endocarditis in susceptible individuals.

3 Aspiration pneumonia. Regurgitation and inhalation of stomach contents may result in pneumonia and lung abscess.

4 Risks to staff of endoscopy units include overt infections from contact with blood, sputum, and gastrointestinal fluids, and the potential hazard of acquiring antibiotic resistant flora.

\section{B Methods for disinfecting endoscopes}

1 Fibrescopes cannot be formally sterilised.

2 Assiduous cleaning is more important than the use of specific disinfectants. Instruments are complex, and effective cleaning requires staff with appropriate training, time, and motivation. Instrument manufacturers and their agents make appropriate recommendations. The process may be facilitated in the future by semi-automatic washing and disinfection machines.

3 Disinfectants. So far, only gluteraldehyde and povidone-iodine have been shown to provide effective disinfection in endoscopy units. Unfortunately, skin sensitivity to gluteraldehyde appears to be a common problem in British endoscopy units, and povidone-iodine is unpleasant to use and may stain the equipment. Seventy per cent alcohol has been recommended as an alternative, and does have proven activity when used after obsessional cleaning; 70\% alcohol may damage the bending section of the endoscope when used externally, and can constitute a fire hazard. Experiments are being conducted with hypochlorite solutions, and various quaternary ammonium compounds.

\section{Recommendations}

1 EQUIPMENT

(a) Endoscopy should be performed only with properly cleaned and disinfected equipment.

(b) Definition and validation of disinfection methods. The methods used in a particular unit should be laid down in collaboration with the hospital microbiologist and infection control officer, with reference to the published literature and manufacturers' instructions. The effectiveness of the 
chosen cleaning and disinfection procedures should be checked by regular microbiological surveys. A method of proven value is outlined below.

(c) Instruments are cleaned according to the manufacturers' instructions. The instrument shaft, suction channel, air channel and water channel, are then soaked in an effective disinfectant for at least 10 minutes. Ancillary equipment is equally important. All ancillaries are dismantled as far as possible and cleaned with a brush and detergent. An ultrasonic cleaning tank is useful. Sterilisation is aimed for wherever possible. The following equipment can be autoclaved: biopsy valves, ERCP catheters (but not stilettes), cytology brushes, metal dilators, splinting tubes, cleaning brushes, bowls, receivers, etc. Equipment which cannot withstand autoclaving should be disinfected by low temperature steam, or immersed in a suitable disinfectant - for example, gluteraldehyde - for as long as possible.

Equipment can become significantly contaminated during storage especially if any water is left in the channels. These procedures are therefore followed before, as well as after, endoscopy lists. Except during lists of potentially infected patients - for example, sphincterotomy for gall stones - the disinfection procedure between endoscopies is often quicker, provided that the regime is bacteriologically validated. Between cases the instrument is cleaned with a detergent; the suction channel is brushed through; the tip of the instrument is cleaned with a toothbrush; the air/ water channel is flushed with water and then air; the shaft of the instrument is immersed in an effective disinfectant which is aspirated into the suction channel and left for two minutes before being rinsed with water and dried. A fresh disinfected biopsy valve is used for each examination.

(d) Infected patients. An instrument which has been used in a patient with a communicable disease - for example, salmonellosis, hepatitis, giardiasis, tuberculosis - requires special attention. It should be cleaned in the usual way and then exposed thoroughly to disinfectant - for example, gluteraldehyde - for at least two hours; alternatively, it can be sterilised using ethylene oxide gas at low pressure after vigorous cleaning.

\section{STAFF AND FACILITIES}

(a) All endoscopists and endoscopy assistants should be made fully aware of the dangers of using contaminated instruments, and should be trained specifically in the care, cleaning, and sterilisation of endoscopic equipment.

(b) Certain minimum standards for endoscopy rooms should be established, bearing in mind the health and safety of staff as well as patients. (c) Staff should be aware of the dangers of sensitivity to disinfectants. Suitable precautions must be made to avoid splashing, and staff should wear gloves when exposed.

\section{PATIENTS}

(a) Immunosuppressed patients. Patients who are effectively immunosuppressed are at greater risk of infective complications. The indication for endoscopy should be reviewed critically; special care should be exercised with a disinfection technique, and the use of prophylactic antibiotics considered.

(b) Endocarditis. There is a theoretical danger of endocarditis developing after gastrointestinal instrumentation in patients with valvular heart disease, and antibiotic prophylaxis has been suggested by analogy with dental procedures. Review of the literature indicates that there are great difficulties in defining real risks and relevant policies, and the committee finds no evidence to support a recommendation for routine antibiotic prophylaxis at present.

(c) ERCP. The use of inadequately disinfected equipment carries particular infection risks in patients submitted to ERCP, especially those with stagnant duct systems - for example, pancreatic cysts, benign or malignant biliary and pancreatic duct stenosis. The introduction of organisms such as Pseudomonas has led to severe septic complications and death. The importance of careful disinfection procedures in these cases cannot be overemphasised. Many patients with duct stones have bile infected with enteric organisms. Most endoscopists recommend prophylactic antibiotics for example, gentamycin and ampicillin - when stagnant ducts or cysts are apparent before or at ERCP: some do not use antibiotics for routine sphincterotomy if the duct is cleared.

\section{RESEARCH}

Further studies are necessary on many aspects of this problem - for example, simplification of instruments to facilitate cleaning and disinfection; better disinfectant solutions and machines; prophylactic antibiotics; protection for staff; certification of endoscopy assistants.

\section{Implications of the recommendations}

Those units which have not (yet) experienced infective problems may question the need for these recommendations, and consider them to be impractical in a busy environment. Many infectious outbreaks have not been officially reported, but there are sufficient publications to indicate that endoscopy with contaminated equipment can be disastrous. There are major medico-legal implica- 
tions. The Endoscopy Committee considers that a new emphasis is necessary. It is no longer adequate to do only what local circumstances permit, but essential to press for the resources to make practicable that which is necessary. This may well mean the appointment of more endoscopy nursing staff, alterations to endoscopy areas, and the purchase of more instruments and accessories.

A T R AXON AND P B COTTON 